\title{
Variants Variants
}

The Journal of the European Society for Textual

Scholarship

\section{$14 \mid 2019$}

Varia

\section{Luca Crispi, Joyce's Creative Process and the}

Construction of Characters in Ulysses. Becoming the

\section{Blooms}

Oxford : Oxford University Press, 2015

\section{Hans Walter Gabler}

\section{(2) OpenEdition}

\section{Journals}

Electronic version

URL: http://journals.openedition.org/variants/726

DOI: $10.4000 /$ variants.726

ISSN: 1879-6095

\section{Publisher}

European Society for Textual Scholarship

Printed version

Number of pages: 186-190

ISSN: 1573-3084

\section{Electronic reference}

Hans Walter Gabler, «Luca Crispi, Joyce's Creative Process and the Construction of Characters in Ulysses. Becoming the Blooms », Variants [Online], 14 | 2019, Online since 10 July 2019, connection on 25 September 2020. URL : http://journals.openedition.org/variants/726 ; DOI : https://doi.org/10.4000/ variants. 726 
Review of Luca Crispi, Joyce's Creative Process and the Construction of Characters in Ulysses: Becoming the Blooms. Oxford: Oxford Univerity Press, 2015. 360 pp. ISBN 978-01-9871-885-7.

"We are still learning to be Joyce's contemporaries, to understand our interpreter". This is the opening sentence of Richard Ellmann's biography with which in 1959 (and identically in the revision of 1982) he drew the sum of his engagement with Joyce's many-faceted life. It has, six decades later, lost neither its truth nor its power. On the contrary: the incentive to such learning has, if anything, intensified. It springs today from a closely-knit material basis witnessing to the very life-forces powering the writer and man. The traces of his working life have survived into our posterity, inscribed in his authorial hand. As the historical, socially and intellectually net-worked subject of biography recedes, it is still what has remained of his writing on paper that has the potential to place us as readers, explorers, analysts and interpreters into an exquisitely privileged contemporaneity with the writer and creative author James Joyce.

In practical terms: over and above the book publications in full of his work, there exist (or have existed, but are mostly still at least mediately definable) several caches of notes, drafts, working manuscripts, fair-copy manuscripts, typescripts, proofs, pre-publications. The contents of his apartment, in rescue dispersed by Paul Léon on Joyce's escape from Paris to Switzerland in 1940, were re-assembled in an exhibition (at La Hune, Paris) in 1949, and from there found their way to the Poetry Collection of the University Libraries, University at Buffalo, State University of New York. What Joyce, before, had left behind in Trieste when relocating to Paris in 1920, now resides by and large in the Cornell Joyce Collection. Assortments of proofs for Ulysses and Finnegans Wake are to be found at Harvard, Buffalo, Princeton (thanks largely to Sylvia Beach) and the University of Texas at Austin. Thanks to Harriet Weaver, much of the richly surviving draft materials for Finnegans Wake, as well as most of what else had accumulated in her care during the 25 years of her association with Joyce, is accessible at the British Library in London. In parallel to this, the fair copy for A Portrait of the Artist as a Young Man which Joyce presented to her went to the National Library of Ireland. This one NLI treasure turned out to be a mere nest egg when, as from about the turn of the millennium, the National Library in Dublin proceeded to acquire not only a major intermediate draft for Ulysses but, more still, a whole array of notes and drafts for Ulysses which, together 
with assorted Finnegans Wake materials, had been successive private gifts from Joyce to Paul Léon during the 1930s. Unsuspected even to exist; they had lain unrecognised for almost seven decades in the basement to the Léons' flat in Paris. This summarily sketchy listing may be eked out by mention of smaller culls of Joyce materials for instance at the Beinecke Library at Yale University, or the Henry E. Huntington Library in Pasadena, California. What has so far remained in private hands (known or anonymously unknown, except to the manuscript curators of the auction houses) are comparatively few individual documents, sometimes perhaps even just a typescript page or two with traces of Joyce's own hand; but also one manuscript in a copybook entitled Eumeo which, at brief public showings when it changed hands, stood revealed not just (unexpectedly) to exist at all, but to be an accretively many-layered and multi-coloured draft - in all likelihood the most intricate progressive material working platform for a Ulysses episode to survive. Ulysses in James Joyce's hand throughout (but for about half of episode 10, Wandering Rocks, which Frank Budgen wrote out at his dictation) is the so-called Rosenbach Manuscript, a pride possession of the Rosenbach Museum and Library in Philadelphia. It is a fair copy for sixteen episodes, to which are integrated two copy-books constituting the final-stage working manuscripts for episodes 17 and 18 (Ithaca and Penelope).

From knowing what there is materially, we may endeavour to learn what it is in itself, and what portals to discovery, insight and understanding it offers. From the materials as they are, as we encounter them and expose ourselves to them, incentives grow afresh to revive traditional competences of critical literary scholarship: skills in manuscript study and in textual criticism - meaning textual criticism as the fundamental analysis of material transmissions, such as it may optionally lead either into scholarly editions, or (more pertinently here) be deployed in the service of criticism. Critical skill so enlarged, in its turn, is likely to respond, moreover, to the very nature of the Joycean materials by extending, with them, into the genetic mode. Luca Crispi's monograph, Joyce's Creative Process and the Construction of Characters in Ulysses: Becoming the Blooms, now provides an exemplary guide to Joyce scholarship and criticism moving anew into such pastures. It is the first full-length study ever attempted to follow closely James Joyce's moves of invention, creation and exploration through the textual landscape out of which, from out of his mind and under his hands, and in progressive encounter with text already (by himself) written, he formed the novel he ultimately saw published under the title Ulysses. With the enterprise of this book, Crispi defines a new mode of scholarly contemporaneity with the author's writerly processes and creative achievement. His investigations, analyses and lucid critical presentations help us to be there as Ulysses progressively happens.

Luca Crispi has long lived in the material environment of the Joyce manuscripts and subsequent documents of transmission. Long before the times, as now, when every researcher into Joyce can view and can work with 
them in digital images, he already experienced them as natural givens to engagement. It is in the first place a natural familiarity with the archival records that Crispi consequently encourages us to attain. His book emphasizes, at the same time, that, and how, the stimulus of familiarity significantly deepens through skills in method and strategies of critical argument. It lays out before us what constant interactive analysis of the written traces of the processes of writing can tell about the genetic shaping of the Joycean texts. In exemplary ways, too, it offers critical conclusions from the analysis: templates for what manner of results may grow out of genetic criticism.

A central template is that of Joyce's story-telling, and of James Joyce, the author, as story-teller. For the book, this provides the framework to hold the strands of narrative matter interwoven in Joyce's art of narrative. "Joyce, the story-teller" is the book's governing thesis: from Crispi's perspective, storytelling constitutes the core impulse for Ulysses. Accordingly, he structures his study out of the book's sub-title, Becoming the Blooms, and unfolds this into the chapter divisions and sub-divisions. In terms of the book's disposition, Crispi hence super-imposes his critical narrative on his subject matter, the written evidence of Joyce's progressive telling by writing Ulysses. From the priority proposition that Joyce first and foremost tells stories springs the notion, secondarily, that "character" and character naming are derivative functions of the story narratives. And indeed, by analysis of the genetic textual materials is shown convincingly again and again that the novel's personnel builds up into coherently narrated characters only from out of the accretion of stories. Consequently, the characters' names tend often not to be primary identifiers, but, in their turn, labels of secondary (or even tertiary) invention for them as actors in the accreted stories.

As the materials of its coming-into-being demonstrate, the invention of Ulysses was a process of constant, ever-fertile enrichment. To deal with what the materials reveal requires critical assessment of what it is that powers the process. What sets free the creative energy? What drives the given elements of text from notes (and whence and how were these taken, in the first place?) into drafting; into draft accretion; into copying-out (i.e., as fair copies, or typescripts, or settings-into-proof)? The initial taking of a note springs often enough (and pervasively, as we know, with Joyce) from reading - all the more, then, it stands to reason that reading, too, triggers each subsequent move along the trajectories the language material takes to coalesce into text. Crispi's analytic argument brings out what is often less than duly considered even in genetic approaches to works and their texts, namely the significant co-creative role of (authorial) re-reading in authoring - whether instant or at later points-in-time of an extended creative process, such as the seven-year or, should its first germs indeed have been laid during Joyce's first sojourn in Paris, the nearly 20-year process of coming-into-being of Ulysses.

The indication of the co-creative role of (authorial) re-reading in authoring is a fundamentally critical insight from textual criticism geared to genetic anal- 
ysis. It distinctly furthers, too, observations specific to increasing the understanding in detail of the work-in-progress. Given that the materials for Ulysses allow for a pretty clear relative timing of the movements of text elements within and across the document network of notes/drafts/typescripts/proofs, it is often possible to determine when a motif, a story modification or extension, even a character first "came to" the progressively writing author. Within the constant writing and (re-)reading process, it is not surprising that this was frequently later than when the latter-day readers, we ourselves in our linear progression through the text, first encounter that element. Genetic analysis quite regularly reveals our "firsts" as moments of authorial late filling-in of narrative exposition, or pro-active preparation of events to come, all "planted" in what may be termed prospective afterthought. Properly so recognised, these moments will commonly even be appreciated as deepenings of our reading experience.

However, for the author so to arrange the text in response to his initial rereadings of the writing-in-progress, was only feasible, if, when the element in question "came to" him, he found the position materially still open where to place its anticipation. But so to compose Ulysses spatially still, up to the point in time when it could be declared finished, was quite early already technically impossible. From the spring/summer 1921 until the last days of January 1922, the production of the printed book and the continued composition of the novel progressed in parallel. Crispi's most drastic example illustrating the impasse this creates in story and character development concerns Lunita Laredo. Had Joyce thought of providing Molly with a mother when actively at work on Calypso, we would as readers also remember her with Molly when she is made to think of her mother in Penelope. In actual fact, however, Lunita Laredo was invented as character and as text only very belatedly in the course of composition of the novel's final episode. Retroactively planting a prospective mention in Calypso, say, was impossible for by the time of writing of Penelope, almost the entire book was already fully printed and its type distributed for re-use. That Lunita Laredo was such a late afterthought has, too, a further serious consequence. Leopold Bloom is through the entire novel oblivious (which attentive readers know) of having, or ever having had, a mother-in-law. Importantly, though, it is not that he has erased her from his memory. Being constructed, as is every character in every fiction, he can hardly be suspected of repressing thoughts and memory of her who was conceptually as well as compositionally never available to go into the constructing of him in the first place.

Correlative story and character construction, then, functions as the warp and weft of Ulysses. This is the bracket thesis which gives further coherence to Luca Crispi's argument for Becoming the Blooms. How is the correlation effected? Its fulcrum is memory. Crispi operatively — and aptly — sub-categorises this into psychological memory and textual memory. Every reader soon catches on to the principle of textual recurrences in Ulysses, and how essential it is combinatorially to grasp them in order to make sense of one's reading experience. 
Appreciating the writing and the narration of Ulysses to the full, however, we also recognise that the fictional characters operate - are constructed - as our mirror-images. Their sense making (whether to themselves or for us) under the terms into which their lives and selves are constructed, is by their, as well as our, reading the world(s) and remembering the experience(s) invented for them. As characters, it is out of an assumed psychological memory that they are constructed into the language that shapes them. But in the pervasively constructed environment of fiction, psychological and textual memory are reciprocally mirrored, for they are together grounded in the language evoking that fiction: psychological memory and textual memory are equally embedded and intertwined in it. This is materially demonstrable from the documented source material of the writing-in-progress of that language, preserved in the notes, drafts, copies, proofs that survive as genetically preparatory to Ulysses and give evidence of the creative energies of invention, writing, (re-) reading and visionary outreach that went into its overall composition.

The monograph Joyce's Creative Process and the Construction of Characters in Ulysses: Becoming the Blooms sets an important mark as paradigm to be emulated in the present phase of Joyce studies in which concern with the genetics of Joyce's works and their texts is distinctly gaining ground. It is Luca Crispi's pioneering achievement to have lucidly and soundly mapped the field in terms both of material substance available to work on and essentially, too, of method. Under the methodological aspect, indeed, his book is to be recommended widely beyond the confines of James Joyce studies as exemplary of how to conduct genetic criticism, and how, and on what manner of material grounds, to teach it. 